\title{
Early Metabolic Outcome After Laparoscopic Sleeve Gastrectomy in Morbid Obese Patients
}

\author{
Tamer M S Salama ${ }^{*}$, Karim Sabry ${ }^{1}$ and Gehan H Eweida ${ }^{2}$
}

Department of General Surgery, Ain Shams University, Egypt

\begin{abstract}
Background: Morbid Obesity $\left(\mathrm{BMI}>40 \mathrm{~kg} / \mathrm{m}^{2}\right)$ is a substantial health problem that is related to many metabolic disorders including diabetes, hypertension and hypercholesterolemia and several cardiovascular diseases. This study we aimed to investigate the early metabolic changes which occur after Laparoscopic Sleeve Gastrectomy.

Methods: One hundred morbid obese patients (65 females and 35 males) aged between 18 to 50 years with BMI range between $40-50 \mathrm{~kg} / \mathrm{m}^{2}$ were enrolled in this study. Patients were followed up after 3 and 6 months after the operation to monitor their BMI, serum glucose level, insulin, serum cholesterol level, triglycerides and systolic blood pressure.
\end{abstract}

Results: A significant correlation was found between the percent decrease in BMI and the percent decrease in the measured metabolic parameters especially cholesterol and triglycerides levels at three and six months postoperatively.

Conclusion: From the above results we can conclude that LSG is not only an effective bariatric procedure for loss of weight but also it plays and important and effective role in correction of metabolic disturbance associated to obesity especially diabetes type 2 very early after the operation.

Statistically analysis used: Continuous variables are expressed as mean and Standard Deviation. Categorical variables are expressed as frequencies and percent. All statistical procedures were carried out using SPSS version 15 for Windows (SPSS Inc, Chicago, IL, USA).

Keywords: Metabolic surgery; Slevee gastrectomy

\section{Introduction}

Morbid Obesity $\left(\mathrm{BMI}>40 \mathrm{~kg} / \mathrm{m}^{2}\right)$ is a substantial health problem that is related to many metabolic disorders including diabetes, hypertension and hypercholesterolemia and several cardiovascular diseases. In addition, morbidly obese patients suffer in performing daily basic activities such as walking or breathing [1]. Worldwide, the condition has perceived significant attention as in the last two decades its incidence has dramatically increased [2].

Currently, bariatric surgery is the best approach to achieve and maintain desirable weight loss and the treatment of weight-related cormorbities [3]. One of the most recent bariatric procedures is Laparoscopic sleeve gastrectomy (LSG) and in some countries it is the most common procedure performed for the treatment of morbid obesity [4]. LSG has gained its preference from the fact that it is a less invasive procedure compared to Gastric bypass and biliopancreatic diversion with the achievement of closely similar weight loss targets $[5,6]$.

Previously, LSG was considered as only a restrictive procedure. However, recently it has been discovered that changes in gut hormonal take place after LSG which allowed its classification as restrictive and hormonal procedure [7].

Most of the studies had focused on the long term metabolic changes that occur after LSG, while far less attention had been made on the early time course of these changes. Therefore in our study we aimed to investigate the early metabolic changes which occur after Laparoscopic Sleeve Gastrectomy.

\section{Patients and Methods}

A prospective study done on one hundred morbid obese patients (65 females and 35 males) aged between 18 to 50 years with BMI range between $40-50 \mathrm{~kg} / \mathrm{m}^{2}$. Laparoscopic sleeve gastrectomy was performed for all patients in the bariatric unit at the general surgery department at El Demerdash Hospital, Ain Shams University in Cairo, Egypt during the time between January 2014 and June 2015. An approval from the ethical committee at the faculty of Medicine at Ain Shams University was obtained.

Patients included in our study had a BMI between $40-50 \mathrm{~kg} / \mathrm{m}^{2}$, complaining from diabetes type 2 plus one more obesity-associated metabolic disorders i.e. hypertension and hypercholesterolemia and underwent two failed trials of weight loss during the year prior to operation.

Patients who had a history of personality disorder, diabetes type 1 , and drug or alcohol addiction, recent cardiac attack, advanced malignancy or underwent a previous bariatric surgery were excluded from our study.

Before the operation, all patients were assessed by a medical team consisting of a physician, bariatric surgeon, psychiatrist, endocrinologist and a dietician to assess their general condition, mental status and obesity-associated co-morbidities such as diabetes (using glucose tolerance test), hypertension or cardiovascular diseases. Moreover, nutritional assessment of patients for vitamin B12, calcium, magnesium, iron, protein, and fat and carbohydrate body composition was performed.

Before performing the operation, all patients wrote an informed

*Corresponding author: Dr Tamer M S Salama, 16 Foud Badwany Street Nas City, Cairo, Egypt, Tel: 01113623458; E-mail: drtamer1981@hotmail.com

Received January 24, 2016; Accepted April 02, 2016; Published April 10, 2016

Citation: Salama TM, Sabry K, Eweida GH (2016) Early Metabolic Outcome After Laparoscopic Sleeve Gastrectomy in Morbid Obese Patients. Surgery Curr Res 6: 266. doi:10.4172/2161-1076.1000266

Copyright: ( 2016 Said TM, et al. This is an open-access article distributed under the terms of the Creative Commons Attribution License, which permits unrestricted use, distribution, and reproduction in any medium, provided the original author and source are credited. 
Citation: Salama TM, Sabry K, Eweida GH (2016) Early Metabolic Outcome After Laparoscopic Sleeve Gastrectomy in Morbid Obese Patients. Surgery Curr Res 6: 266. doi:10.4172/2161-1076.1000266

consent. During the week prior to surgery, patients were instructed to eat a high protein diet with regular exercise and the day before operation they were allowed to only take clear fluids. All operation procedures were performed by laparoscopy. Intra-operatively, patients were intubated in supine position, pneumoperitoneum was established through $10 \mathrm{~mm}$ umbilical visiport, one $5 \mathrm{~mm}$ trocar was placed under xiphoid process for the insertion of the liver retractor, 12 and15 $\mathrm{mm}$ trocars were placed on the right and left middle clavicular lines respectively for the surgeon instruments and another $5 \mathrm{~mm}$ trocar was placed on the left anterior axillary line for assistance.

Oral Ryle was inserted to deflate the stomach which makes the dissection easier. Dissection started on the greater curve $5 \mathrm{~cm}$ from pylorus up to the cardio-oesophageal junction very close to the stomach. Meticulous dissection was performed at the angle of Hiss until full mobilization of the gastric fundus was achieved (Figure 1). After the stomach was freed from the great curvature, a 38-French orogastric tube was inserted in the stomach until it entered the duodenum (Figure 2). The stomach was then resected using linear staplers which were applied parallel to the lesser curve starting 3-5 cm from the pylorus up to the angle of Hiss (Figure 3,4). Hemostasis and staple line were checked using methylene blue and the resected stomach was then removed through the left midclavicilar port. The residual gastric volume ranged from 80 to $100 \mathrm{ml}$. Drains were left for 24 hours.

Postoperative standard clinical protocol was used for all patients. All patients were on "nil by mouth" for 48 hours followed by lowcaloric clear liquids for 1 week and low-caloric semisolid food for 2-4 weeks. Full diet was subsequently introduced. All patients were asked to resume work after one week of operation and to perform gradual exercise and physical activity after two weeks of operation.

Patients were discharged from the hospital in the third day after operation. Gastrographin study was performed for all patients before discharge. Patients were followed up after 3 and 6 months post operation to monitor their BMI, serum glucose level 2 hour postprandial, insulin, serum cholesterol level, triglycerides and systolic blood pressure.
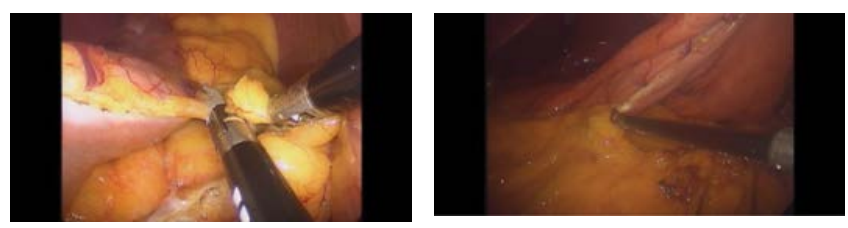

Figure 1: Dissecting stomach from greater curve up to angle of Hiss and down to $3 \mathrm{~cm}$ from pylorus.

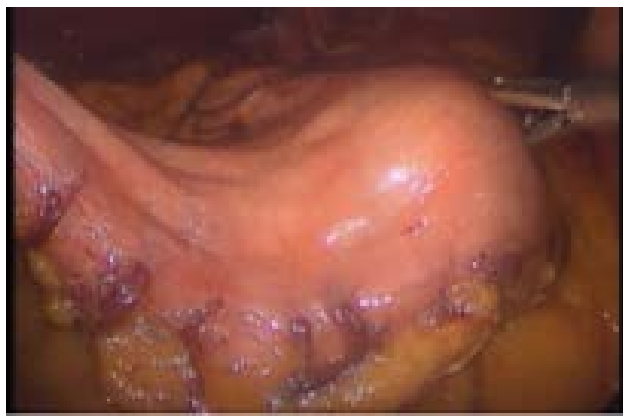

Figure 2: Insertion of $38 \mathrm{fr}$ bougie.

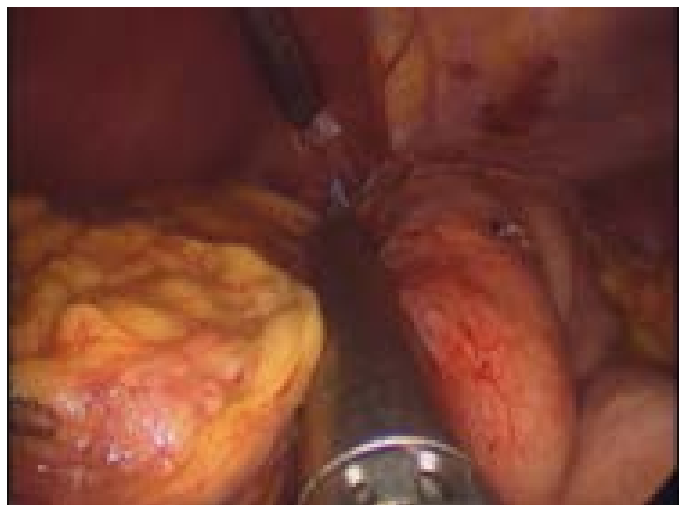

Figure 3: Stapling stomach around bougie.

\begin{tabular}{|l|l|l|l|l|l|}
\hline \multicolumn{2}{|l|}{} & Mean & ISD & Minimum & Maximum \\
\hline Age & & 41.1 & 7.93 & 18.00 & 50.00 \\
\hline \multirow{2}{*}{ Sex } & Male (n \%) & 35 & $35 \%$ & & \\
\cline { 2 - 6 } & Female (n \%) & 65 & $65 \%$ & & \\
\hline
\end{tabular}

Table 1: Description of socio-demographic data among cases.

\begin{tabular}{|c|c|c|c|c|c|c|}
\hline $\mathbf{K g} / \mathbf{m}^{2}$ & Mean & $\mathbf{I S D}$ & Minimum & Maximum & $\begin{array}{c}\text { Percent } \\
\text { of change } \\
\text { after } \\
\text { surgery }\end{array}$ & \%EWL \\
\hline BMI Baseline & 46.2 & 5.7 & 40 & 50 & & \\
\hline BMI after 3 month & 39.3 & 4.3 & 36.7 & 45 & $14.9 \%$ & $32.5 \%$ \\
\hline BMI after 6 month & 35.4 & 3.9 & 31.9 & 39.5 & $23.3 \%$ & $50.9 \%$ \\
\hline
\end{tabular}

Table 2: Description of BMI at baseline, 3, 6 months after surgery.

\begin{tabular}{|c|c|c|c|c|c|}
\hline Mg/dl & Mean & $\mathbf{\pm S D}$ & Min & Max & $\begin{array}{c}\text { Percent of change } \\
\text { after surgery }\end{array}$ \\
\hline Glucose Baseline & 220.5 & 32.68 & 160 & 320 & \\
\hline Glucose after 3 month & 152.2 & 12.64 & 130 & 245 & $30.9 \%$ \\
\hline Glucose after 6 month & 120.3 & 19.81 & 95 & 160 & $45.5 \%$ \\
\hline
\end{tabular}

Table 3: Description of glucose at baseline, 3, 6 months after surgery.

\begin{tabular}{|c|c|c|c|c|c|}
\hline IU/ML & Mean & ISD & Min & Max & $\begin{array}{c}\text { Percent of change } \\
\text { after surgery }\end{array}$ \\
\hline Insulin baseline & 21.6 & 5.4 & 12 & 32 & \\
\hline Insulin after 3 month & 15.5 & 3.7 & 7 & 25 & $28.2 \%$ \\
\hline Insulin after 6 month & 10.8 & 4.2 & 5 & 17 & $45.5 \%$ \\
\hline
\end{tabular}

Table 4: Description of insulin at baseline, 3, 6 months after surgery.

\begin{tabular}{|c|c|c|c|c|c|}
\hline Mg/DI & Mean & ISD & Min & Max & $\begin{array}{c}\text { Percent of change } \\
\text { after surgery }\end{array}$ \\
\hline Triglyceride Baseline & 185.5 & 23.1 & 100 & 250 & \\
\hline Triglyceride after 3 month & 130.4 & 20.6 & 80 & 195 & $29.7 \%$ \\
\hline Triglyceride after 6 month & 85.7 & 18.6 & 55 & 135 & $53.8 \%$ \\
\hline
\end{tabular}

Table 5: Description of triglyceride at baseline, 3, 6 months after surgery

\section{Results}

One hundred adult patients comprising 65 females and 35 males, aged between 18 and 50 years and suffering from morbid obesity (BMI $40 \mathrm{~kg} / \mathrm{m}^{2}$ ) with 2 or more metabolic complications were enrolled in this 


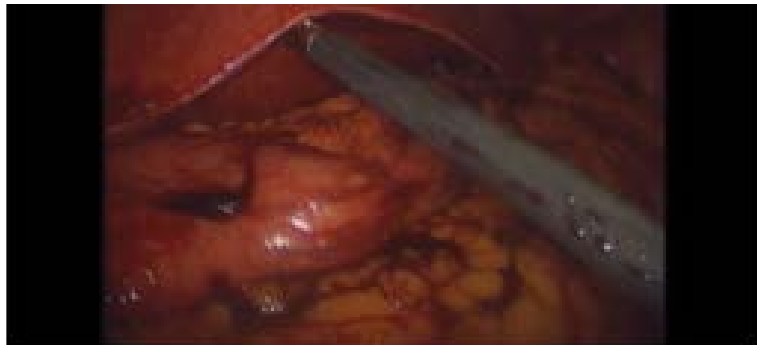

Figure 4: Sleeve gastrectomy.

study (Table 1).

After the operation by three and six months, the mean BMI of our patients decreased by $14.9 \%$ and $23.3 \%$ respectively, the mean glucose level was decreased by $30.9 \%$ and $45.5 \%$ respectively, the mean insulin level was decrease by $28.2 \%$ and $45.5 \%$ respectively, the mean triglycerides level was decreased by $29.7 \%$ and $53.8 \%$ respectively, the mean cholesterol level was decreased by $27.4 \%$ and $46.6 \%$ respectively and the mean systolic blood pressure was decreased by $12.8 \%$ and $19.4 \%$ respectively (Tables $2-7$ ).

Six months after the operation, we found that $75 \%$ of our patients who had impaired glucose tolerance test returned to normal glucose levels, $60 \%$ of patients who were on oral hypoglycemic drugs required decreased drug doses, while $40 \%$ of them stopped the treatment and $63.7 \%$ of patients who were on insulin medication required decreased insulin doses, while $36.3 \%$ of them shifted to oral hypoglycemic drugs (Table 8).

A significant correlation was found between the percent of decrease in BMI and the percent of decrease in the measured metabolic parameters especially cholesterol and triglycerides levels at three and six months postoperatively (Tables 9 and 10).

No intra or postoperative complications were observed and no mortality occurred.

\section{Discussion}

Currently laparoscopic sleeve gastrectomy is one of the most preferred bariatric surgeries for weight loss due to its minimal complications compared to other procedures and its associated metabolic effect [8].

Many studies have extensively investigated the long term effects of laparoscopic sleeve gastrectomy on controlling glucose levels in diabetic patients where $70 \%$ of LSG patients are cured in the long term, while the rest of the patients show improvement [9]. This study aims to focus on the early or short term metabolic effects of laparoscopic sleeve gastrectomy.

Our results showed that the decrease in mean BMI at 3 and 6 months after the operation was $6.9 \mathrm{~kg} / \mathrm{m}^{2}$ and $10.8 \mathrm{~kg} / \mathrm{m}^{2}$ respectively, while the decrease in mean EWL at 3 and 6 months after the operation was $32.5 \%$ and $50.9 \%$ respectively. Our results agree with that published by Rosenthal et al. [10] in which they reported that 30 patients with a mean preoperative BMI value of $41.4 \mathrm{~kg} / \mathrm{m}^{2}$ had a decrease in the mean EWL by $40.7 \%$ and $52.8 \%$ at 3 and 6 months after operation respectively. Another study performed by Hutter et al. [11] showed that the average reduction in the mean BMI for patients undergoing LSG was $8.75 \mathrm{~kg} /$ $\mathrm{m}^{2}$ at 6 months and $11.87 \mathrm{~kg} / \mathrm{m}^{2}$ at 1 year post operation.
In this study we found a positive correlation between the decrease of patients mean BMI and the improvement in their metabolic parameters after LSG where the mean glucose and insulin levels declined from $220.5 \mathrm{mg} / \mathrm{dI}$ and $21.6 \mathrm{IU} / \mathrm{ml}$ preoperative to $152.2 \mathrm{mg} / \mathrm{dI}(30.9 \%$ decrease) and $15.5 \mathrm{IU} / \mathrm{ML}$ (28.2\% decrease) respectively at 3 months post operation and declined to $120.3 \mathrm{mg} / \mathrm{dI}$ (45.5\% decrease) and 10.8 IU/ML ( $45.5 \%$ decrease) at 6 months after the operation respectively. The observed improvement in insulin response was mainly because of: the decrease in weight and low caloric intake decreased inflammatory mediators [4] and decreased Ghrelin production which has diabetic effects where its suppression can lead to improved glucose metabolism [12].

In our study after performing LSG: $75 \%$ of patients who had impaired glucose tolerance test, their glucose levels returned to normal, $40 \%$ of patients who were on oral hypoglycemic drugs stopped their medications and the rest of them required lesser doses at 6 months post operation compared to that before the operation and $36.3 \%$ of patients who were on insulin treatment shifted to oral hypoglycemic drugs, while the rest of them required decreased insulin doses at 6 months post operation compared to that prior to the operation. In a review prepared by Gill et al. [9], they stated that $66.2 \%$ of patients who underwent sleeve gastrectomy were completely cured from type 2 diabetes which was reflected by an overall improvement in fasting glucose levels and HbAlc levels allowing the termination of all diabetic medications. In another study performed at Cleveland clinic [13] in which they compared sleeve gastrectomy (SG) to medical management on type 2 diabetic patients, they found that not only there was a significant reduction in the use of oral hypoglycemic drugs but also after 1 year of follow-up only $8 \%$ of SG patients required insulin.

A study performed by Zhang et al. [14] showed that highdensity lipoprotein cholesterol (HDL) and triglycerides (TRIG) were significantly improved after LSG but low-density lipoprotein cholesterol (LDL) and total cholesterol were not improved. In another study conducted by Videl et al. [15] they found that the improvements in HDL and TRIG levels observed after LSG were closely similar to those observed after gastric bypass. These results agree with our results where we found that the mean triglyceride and cholesterol levels were decreased from $185.5 \mathrm{mg} / \mathrm{dL}$, and $240.3 \mathrm{mg} / \mathrm{dL}$ preoperatively to $130.4 \mathrm{mg} / \mathrm{dL}$ and $174.4 \mathrm{mg} 3$ months postoperatively/dL respectively ( $29.7 \%, 27.4 \%$ decrease from the mean level ) and decreased at 6 months postoperatively to $85.7 \mathrm{mg} / \mathrm{dL}$ and $128.2 \mathrm{mg} / \mathrm{dL}(53.8 \%$, $46.6 \%$ decrease in main level).

The mean systolic blood pressure in our patients was decreased from $155.4 \mathrm{mmHg}$ preoperatively to $135.4 \mathrm{mmHg}$ ( $12.8 \%$ decrease from the main level ) at 3 months after the operation and decreased to 125.2 $\mathrm{mmHg}(19.4 \%$ decrease in the main level ) at 6 months postoperatively. Our results agree with those published by Buchwald et al. [16] where they reported that $78.5 \%$ of patients underwent LSG had resolution or improvement in their hypertension.

No intra or postoperative complication or mortality after the operation which indicates that LSG is a safe and simple procedure.

\section{Conclusion}

From the above results we can conclude that LSG is not only an effective bariatric procedure for loss of weight but also it plays and important and effective role in correction of metabolic disturbance associated to obesity especially diabetes type 2 very early after the operation. 
Citation: Salama TM, Sabry K, Eweida GH (2016) Early Metabolic Outcome After Laparoscopic Sleeve Gastrectomy in Morbid Obese Patients. Surgery Curr Res 6: 266. doi:10.4172/2161-1076.1000266

Page 4 of 5

\begin{tabular}{|c|c|c|c|c|}
\hline Mg/DI & Mean & $\mathbf{\pm S D}$ & Minimum & Maximum \\
\hline cholesterol Baseline & 240.3 & 33.1 & 140 & 300 \\
\hline cholesterol after 3 month & 174.4 & 24.6 & 110 & 220 \\
\hline cholesterol after 6 mo nth & 128.2 & 23.1 & 70 & 160 \\
\hline
\end{tabular}

Table 6: Description of cholesterol at baseline, 3, 6 months after surgery

\begin{tabular}{|c|c|c|c|c|}
\hline $\mathbf{m m H g}$ & Mean & $\mathbf{\pm S D}$ & Minimum & Maximum \\
\hline SBP Baseline & 155.4 & 15.7 & 120 & 180 \\
\hline SBP after 3 month & 135.4 & 11.7 & 120 & 150 \\
\hline SBP after 6 month & 125.2 & 5.2 & 120 & $12.8 \%$ \\
\hline
\end{tabular}

Table 7: Description of SBP at baseline, 3, 6 months after surgery

\begin{tabular}{|c|c|c|c|c|c|c|c|}
\hline & & \multicolumn{6}{|c|}{ After surgery } \\
\hline & & Glucose & Insulin & TG & Cholesterol & SBP & DBP \\
\hline \multirow{3}{*}{ BMI after 3 month } & $\mathrm{R}$ & .422 & .436 & .513 & .591 & .410 & .496 \\
\hline & $\mathrm{P}$ & $<0.05$ & $<0.05$ & $<0.01$ & $<0.01$ & $<0.05$ & $<0.05$ \\
\hline & Sig. & $\mathrm{S}$ & $\mathrm{S}$ & HS & HS & $S$ & $S$ \\
\hline
\end{tabular}

Table 8: Correlation between 3 month after surgery BMI and all other parameters 3 month after surgery

\begin{tabular}{|c|c|c|c|c|c|c|c|}
\hline & & \multicolumn{6}{|c|}{ At follow up } \\
\hline & & Glucose & Insulin & TG & Cholesterol & SBP & DBP \\
\hline \multirow{3}{*}{ BMI after 6 month } & $\mathrm{R}$ & .465 & .491 & .565 & .613 & .459 & .466 \\
\hline & $\mathrm{P}$ & $<0.05$ & $<0.05$ & $<0.01$ & $<0.01$ & $<0.05$ & $<0.05$ \\
\hline & Sig. & $S$ & $S$ & HS & HS & $S$ & $S$ \\
\hline
\end{tabular}

Table 9: Correlation between 6 month after surgery BMI and all other parameters 6 month after surgery

\begin{tabular}{|c|c|c|c|c|}
\hline Preoperative state & Post-operative state & $\mathbf{N}$ & $\%$ & Total number $\%(n=100)$ \\
\hline \multirow{2}{*}{ Impaired glucose tolerance $(n=20)$} & Complete cure & 15 & $75 \%$ & $15 \%$ \\
\hline & No change & 5 & $25 \%$ & $5 \%$ \\
\hline \multirow{2}{*}{ Oral hypoglycemic $(n=25)$} & Stop treatment & 10 & $40 \%$ & $10 \%$ \\
\hline & Decrease oral dose & 15 & $60 \%$ & $15 \%$ \\
\hline \multirow{2}{*}{ Insulin $(n=55)$} & Shift to oral hypoglycemic & 20 & $36.3 \%$ & $20 \%$ \\
\hline & Decrease insulin dose & 35 & $63.7 \%$ & $35 \%$ \\
\hline
\end{tabular}

Table 10: Diabetic status of the patients preoperative and 6 months after the operations

\section{Conflict of Interest Statement}

No any type of conflict of interest

\section{Ethical Approval}

An approval from the ethical committee at the faculty of Medicine at Ain Shams University was obtained to this study.

\section{Informed Consent}

Informed consent was obtained from all individual participants included in the study.

\section{References}

1. Mensah GA, Mokdad AH, Ford E, Narayan KM, Giles WH, et al. (2004) Obesity, metabolic syndrome, and type 2 diabetes: emerging epidemics and their cardiovascular implications. Cardiol Clin 22: 485-504.
2. Buchwald H, Ikramuddin S, Dorman RB, Schone JL, Dixon JB (2011) management of the metabolic/bariatric surgery patient. Am J Med124: 10991105.

3. Kiriakopoulos A, Varounis C, Tsakayannis D, Linos D (2009) Laparoscopic sleeve gastrectomy in morbidly obese patients: Technique and short term results. HORMONES 8: 138-143.

4. Jadhav S, Borude S (2013) Effect of Laparoscopic Sleeve Gastrectomy on Weight Loss And Co-Morbid Factors. The Internet Journal of Surger 29: 1

5. 5. Brethauer SA, Hammel JP, Schauer PR (2009) Systematic review of sleeve gastrectomy as staging and primary bariatric procedure. Surg Obes Relt Dis 5: $469-475$.

6. Chen B, Kiriakopoulos A, Tsakayannis D, Wachtel MS, Linos D, et al. (2009) Reinforcement does not necessarily reduce the rate of staple line leaks after sleeve gastrectomy. A review of the litera- ture and clinical experiences. Obes Surg 19: 166-172. 
Citation: Salama TM, Sabry K, Eweida GH (2016) Early Metabolic Outcome After Laparoscopic Sleeve Gastrectomy in Morbid Obese Patients. Surgery Curr Res 6: 266. doi:10.4172/2161-1076.1000266

7. Noah J, Smith A, Birch D, Karmali S (2013) The Metabolic Effects of Laparoscopic Sleeve Gastrectomy: A Review. J Minim Invasive Surg Sci 2: 3-7.

8. Gagner M, Deitel M, Kalberer TL, Erickson AL, Crosby RD (2009) The Sec- ond International Consensus Summit for Sleeve Gastrectomy. Surg Obes Relat Dis 5: 476-485.

9. Gill RS, Birch DW, Shi X, Sharma AM, Karmali S (2010) Sleeve gastrectomy and type 2 diabetes mellitus: a systematic review. Surg Obes Relat Dis 6: 1-10.

10. Roa PE, Kaidar-Person O, Pinto D, Cho M, Szomstein S (2006) Laparoscopic sleeve gastrectomy as treatment for morbid obesity: technique and short-term outcome. Obes Surg 16: 1323-1326.

11. Hutter MM, Schirmer BD, Jones DB, Ko CY, Cohen ME, et al. (2011) First report from the American College of Surgeons Bariatric Surgery Center Network: laparoscopic sleeve gastrectomy has morbidity and effectiveness positioned between the band and the bypass. Ann Surg 254:410-420.
12. Thaler JP, Cummings DE (2009) Minireview: hormonal and metabolic mechanisms of diabetic remission after GI surgery. Endocrinology 150: 25182525

13. Schauer PR, Kashyap SR, Wolski K Brethauer SA, Kirwan JP, Pothier CE, et al. (2012) Bariatric surgery versus intensive medical therapy in obese patients with diabetes. N Engl J Med 366: 1567-1576.

14. Zhang F, Strain GW, Lei W, Dakin GF Gagner M, et al. (2011) Changes in lipid profiles in morbidly obese patients after laparoscopic sleeve gastrectomy (LSG). Obes Surg 21: 305-309.

15. Vidal J, Ibarzabal A, Romero F, Delgado S, Momblan D, et al. (2008) Type 2 diabetes mellitus and the metabolic syndrome following sleeve gastrectomy in severely obese subjects. Obes Surg 18: 1077-1082.

16. Buchwald H, Avidor Y, Braunwald E, Jensen MD, Pories W, et al.(2004) Bariatric surgery: a systematic review and meta- analysis. JAMA 292: 1724-1737. 